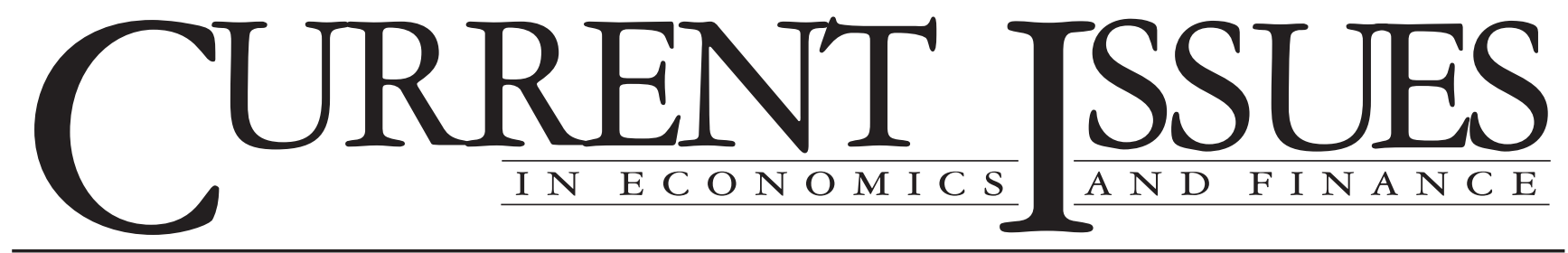

April 1997

Volume 3 Number 6

\title{
Are There Good Alternatives to the CPI?
}

Charles Steindel

Critics of the consumer price index - the most widely watched inflation measure-contend that it overstates inflation by as much as 1 percentage point a year. Some have argued that alternative indexes eliminate the CPI's upward bias and offer a more accurate reading of inflation levels. A closer look at these alternatives, however, reveals that they have substantive problems of their own, suggesting that the CPI, though flawed, is still our most reliable indicator of changes in inflation.

The U.S. economy has enjoyed fifteen years of disinflation. As growth in living costs trends downward and the goal of price stability seems attainable, policymakers are increasingly concerned with the precision of their inflation measures. Differences between existing price series have assumed new importance, and the search is on for the most reliable indicator of our progress toward stable prices.

The most widely watched inflation series at present, the consumer price index (CPI), puts inflation in the neighborhood of 3 percent. Many observers contend, however, that we are much closer to price stability than the CPI would suggest. In their view, the CPI tends to overstate the true rate of inflation by about 1 percentage point a year. ${ }^{1}$ Support for this interpretation comes from other inflation measures such as the chain-weighted price indexes for gross domestic product (GDP) and personal consumption expenditures (PCE), which have been recording inflation rates as much as 1 percentage point lower than the CPI's rate.

In response to concerns that the CPI is upwardly biased, a group of scholars appointed by the Senate Finance Committee has made recommendations for improving the index (Boskin et al. 1996). In addition, Federal Reserve Chairman Alan Greenspan has proposed that a commission be charged with assessing the growth in the true cost of living each year. The commis- sion's estimates would be used in place of the CPI to set cost-of-living allowances for social security recipients and to adjust tax brackets and personal exemptions (Greenspan 1997).

This edition of Current Issues examines whether alternative measures - specifically, the chain-weighted GDP and PCE indexes - provide a better fix on inflation than the CPI does. If either measure is in fact superior to the CPI, policymakers might rely on it to track inflation, index benefits, and set tax brackets. The analysis reveals, however, that both alternative indicators have problems at least as serious as those of the CPI-which, despite its flaws, still appears to be, of all inflation measures, "the best currently available" (Boskin et al. 1996).

\section{Measuring Inflation}

Economic theory offers clear guidelines on the proper measurement of inflation. If inflation is defined as the increase in a household's cost of living, then an inflation measure should capture the increase in current-dollar income necessary to allow a consumer to purchase a bundle of goods and services that will leave him or her as satisfied now as in the prior period. To calculate the additional income needed to maintain this level of satisfaction, analysts need to construct an aggregate price index that meets the following criteria: 
- It should record only those costs that contribute directly to consumer satisfaction in the period specified. For instance, the full purchase price of a new car should not be included, since the car will be used for a long time, but the costs of owning a car over the period, such as depreciation costs and auto loan interest costs, should be taken into account.

- The measure of price change for an individual item should correct for changes in quality or other characteristics, such as changes in the material in a shirt.

- Growth in the index should take into account changes in the composition of consumer expenditures over time. Indexes that account for these changes according to certain criteria, such as the chain-weighted GDP and PCE indexes, are said to be superlative indexes; indexes such as the CPI are known as Laspeyres indexes (see box).

\section{The CPI and Its Rivals}

The CPI, compiled by the U.S. Labor Department's Bureau of Labor Statistics (BLS), has been the benchmark measure of U.S. inflation since World War I. Over the years, BLS has updated and improved both the design of the CPI and the procedures used to collect prices of individual items used in the index. These procedures have now reached very high degrees of sophistication (Bureau of Labor Statistics 1992; Boskin et al. 1996).

The CPI is a monthly measure, usually released about three weeks after the end of each month. It is revised only to account for changes in seasonal adjustment factors. ${ }^{2}$ In contrast, the PCE index for each month is released a week or two after the CPI and is

\section{The CPI, compiled by the U.S. Labor Department's Bureau of Labor Statistics, has been the benchmark measure of U.S. inflation since World War I.}

subject to continual revision, not only to account for changes in seasonal adjustment factors, but also for reasons such as changes in estimates of consumer spending patterns. The GDP index-released a day ahead of the monthly PCE—is compiled only for quarterly data and is also subject to continual revision.

Despite its enhancements over the years, the CPI still has considerable problems as an inflation measure. For instance, the index overstates many individual price

\section{Types of Price Indexes}

Laspeyres: A Laspeyres index measures the current cost, relative to the past cost, of a particular bundle of goods and services consumed or produced some time in the past, known as the base period. The CPI is a Laspeyres index. Growth in a Laspeyres index is a weighted average of growth in the cost of each item, with the weights directly related to the increase in the price of each item since the base period. A Laspeyres index tends to overstate inflation because it does not take into account a household's willingness and ability to reduce its consumption of items whose prices are rising rapidly.

Paasche: A Paasche index measures the current cost, relative to the past cost, of the currently consumed bundle of goods and services. Growth in a Paasche index understates inflation because current spending patterns reflect in part household consumption of more of some items simply because their prices are rising more slowly.

Superlative: Superlative indexes are designed to correct the problems of both the Laspeyres and Paasche indexes. In the last twenty years, a compelling theoretical case has been made for the use of superlative indexes (Diewert 1976, 1987).

There are two major indexes of this type: the Fisher Ideal index and the Tornqvist index. The Fisher Ideal index for a period is the geometric average of the corresponding Laspeyres and Paasche indexes. The GDP and PCE indexes are "linked" or "chained" Fisher Ideal indexes." Growth in the Tornqvist index is computed as a weighted average of price increases for individual items, with the weights being the average of the corresponding weights in the growth of the Laspeyres and Paasche indexes. There is little real difference in the design of, or the estimates made by, the two superlative measures.

The superlative indexes yield very good approximations of true inflation. Nevertheless, the indexes present one important practical difficulty: their calculations of inflation in a period rely on the Paasche price index, which cannot be computed until the period ends and the pattern of expenditures has been observed. Superlative indexes therefore can only be estimated, not observed, on an ongoing basis.

* The terms come from the annual updating of the Laspeyres index base period and the linking or chaining of the computed annual growth rates to build the reported index, with the value of the index set at 100 for some arbitrary year. 


\section{Chart 1 \\ Comparison of the Growth Rates of the CPI and the GDP Index}

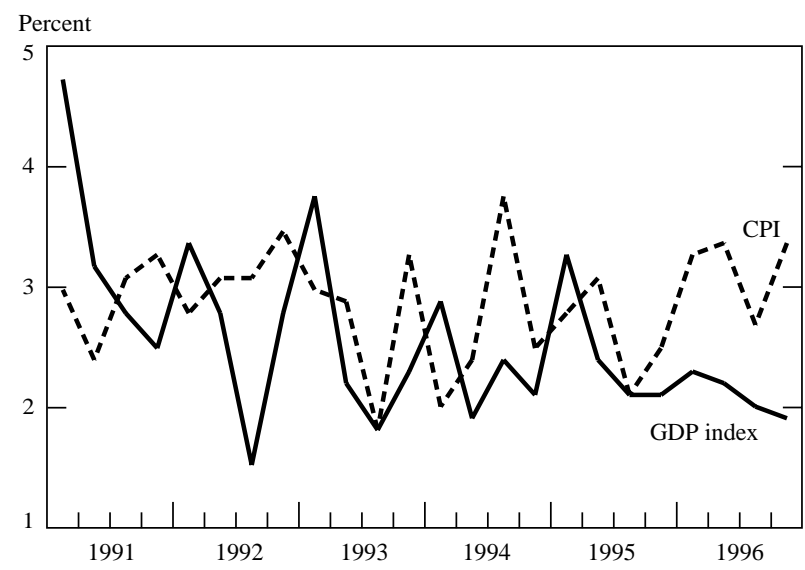

Sources: U.S. Department of Labor, Bureau of Labor Statistics; U.S. Department of Commerce, Bureau of Economic Analysis.

Note: The CPI growth rate is calculated as the quarterly annualized change.

increases by failing to fully adjust posted price changes for quality improvements and by underestimating the growth of sales by discount retailers. ${ }^{3}$ Furthermore, the techniques used by BLS to combine individual price changes into an aggregate measure can also result in an overstatement of inflation. The CPI's growth is computed as the increase in the cost of a group of goods and services selected on the basis of 1982-84 surveys of household spending. This procedure does not take into account a consumer's ability to offset part of the discomfort caused by any one item's price increase by purchasing less of that item and more of another one (for instance, by buying more chicken following an increase in beef prices). ${ }^{4}$ In other words, the true cost of living will not grow as fast as the CPI, even if we correct for the CPI's overstatements of individual price changes.

Further compromising the $\mathrm{CPI}$ as a measure of the cost of living is its incorporation, in contradiction of economic theory, of the purchase price of numerous long-lived goods, such as cars and furniture, rather than the cost of owning these items over time. It is not clear, however, whether this practice adds to or subtracts from the CPI's overstatement of inflation.

In addition, the CPI is not a reliable measure of inflation over long time periods. Changes in procedures used by BLS to collect individual prices have made it difficult for analysts to compare CPI inflation data from earlier periods with data from the current period. For instance, CPI data from the 1970s and the 1990s differ markedly because of changes in the way housing prices are calculated. Even from year to year, smaller changes in data collection methods make comparisons problematic.
The GDP Index. In light of the CPI's problems, it is worth looking at other inflation measures, one of which is the chain-weighted price index for GDP. This series, compiled by the U.S. Commerce Department's Bureau of Economic Analysis (BEA), is a measure of the cost of all goods and services produced in the United States. Annual growth in the GDP index is computed using the superlative Fisher Ideal method (see box). ${ }^{5}$ Over the last few years, the GDP measure has typically grown less rapidly than the CPI (Chart 1). Since the GDP index is more comprehensive than the CPI (it includes prices for more items), is designed in accordance with standard price index theory, and seems less biased than the CPI in recent years (because of its less rapid growth), it appears to be a better measure of inflation.

Despite its superficial advantages, upon examination the GDP price index appears no better, and may well be worse, than the CPI. On balance, the more comprehensive nature of the GDP index is most likely a disadvantage. To a greater extent than the CPI, the GDP index includes the acquisition prices of long-lived goods and structures. As noted earlier, the inclusion of these prices compromises a price index's ability to track the cost of living. Moreover, the GDP index includes many "one-of-a-kind" items, such as factories, that are quite difficult to price. It also includes very hard-to-measure prices from the government sector: for example, how does one price the protective services of the armed forces?

Another drawback of the GDP index is that it measures the prices of goods and services produced in the United States - as opposed to the CPI, which measures the prices of goods and services purchased by

\section{Despite its superficial advantages, upon examination the GDP price index appears no better, and may well be worse, than the CPI.}

Americans. This distinction is important because the prices of exports are included in the GDP index, but the prices of imports are not-at least not directly. ${ }^{6}$ An inflation index aimed at measuring the costs incurred by Americans should use the CPI's procedure of including import prices but excluding export prices.

Furthermore, the GDP index is not really independent of the CPI, since it uses a great deal of CPI data-for instance, data on food and clothing costs - to measure the prices of many items. Hence, the GDP index shares many of the CPI's technical flaws. Of course, the incorporation 


\section{Chart 2 \\ Comparison of the Growth Rates of the CPI
and the PCE Index}

Percent

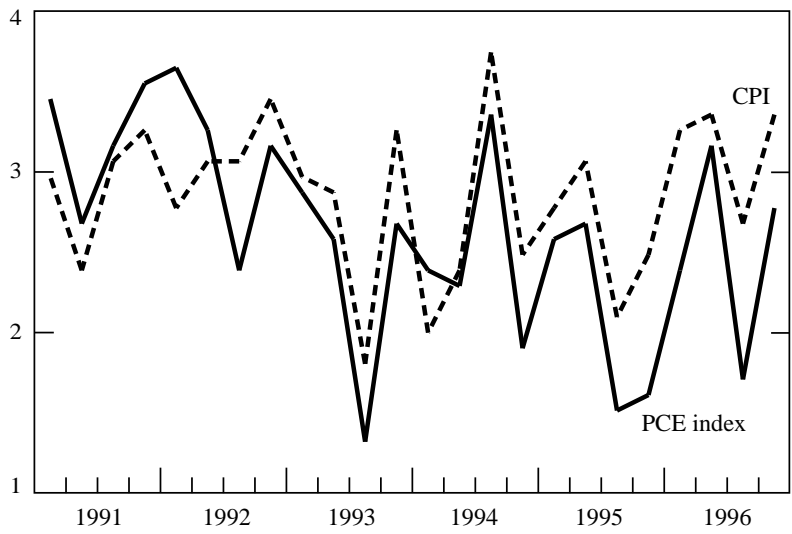

Sources: U.S. Department of Labor, Bureau of Labor Statistics; U.S. Department of Commerce, Bureau of Economic Analysis.

Note: The CPI growth rate is calculated as the quarterly annualized change.

of CPI data does not by itself make the GDP index an inferior inflation measure.

The PCE Index. Many problems with the GDP index stem from its inclusion of prices for items not purchased by consumers. Therefore, the price index for the consumer portion of the GDP series-the chainweighted PCE price index, also compiled by the BEAmight appear to be a good alternative to the CPI. The $\mathrm{CPI}$ and the PCE are measures of aggregate prices for a very similar bundle of goods and services and, to a large extent, the PCE uses the same data as the CPI to price individual items. ${ }^{7}$ Despite these similarities, growth in the PCE is generally a bit lower than growth in the CPI (Chart 2), so the PCE-like the GDP index-appears to remove much of the CPI's upward bias.

A major difference between the PCE index and the CPI is the PCE's purported use of the superlative Fisher Ideal technique to combine individual price increases into aggregate inflation. For this reason alone, it would seem that the PCE index is a better inflation measure than the CPI. However, on further examination, the advantages of the PCE are less clear-cut. For example, the initial estimates of the PCE series are actually not computed by the Fisher Ideal technique, because as noted in the box, the technique cannot be readily applied to incoming data. Instead, the inflation measure used to calculate the initial estimates is the growth in the cost of a bundle of goods and services reflecting recent expenditure patterns. Hence, the PCE, as it is first published, is a Laspeyres index similar to the CPI (Landefeld and Parker 1995). This procedure gives some upward bias to preliminary readings of growth in the PCE index, though probably not as much as in the case of the CPI.

Moreover, revised values of the PCE index are imperfect estimates of the Fisher Ideal price index. The PCE measure uses the real consumption expenditures data of the BEA's National Income and Product Accounts to proxy for expenditure patterns. These data are just revisable estimates of current spending patterns (Shapiro and Wilcox 1996b; Triplett 1996).

Correct estimation of spending patterns is a practical as well as an academic issue. Over the past two years, CPI growth has edged up while PCE growth has remained largely unchanged. In the PCE index, increases in food and energy prices have been offset by moderation in other areas, most notably in the cost of medical care. In the CPI, accelerated food and energy price increases have not been fully offset elsewhere, in part because the CPI gives less weight to the medical cost slowdown. It is perfectly conceivable, however, that future data revisions will lessen the impact of the medical cost slowdown on the PCE index, and this measure too may exhibit a modest pickup in the $1995-96$ period $^{8}$

Although the PCE index may ultimately show a clear superiority to the CPI, thus far it has not done so. The advantages of the PCE may lie more in its conceptual design than

\section{Although the PCE index may ultimately show a clear superiority to the CPI, thus far it has not done so.}

in the published data themselves - particularly the initial estimates. While the PCE may be a better measure of the average pace of inflation than the CPI over some prolonged period, the uncertainty surrounding the PCE's preliminary readings suggests that it may not be any better at detecting period-to-period changes in inflation. In many policy contexts, knowing that inflation has increased over a period of time can be more valuable than knowing its precise average rate over the last year or so.

\section{Conclusion}

The CPI clearly has its faults - most notably, it probably overstates the true pace of inflation. However, recent research has greatly increased our understanding of the CPI's problems and can help us monitor the incoming data better and guide improvements in the index. ${ }^{9}$

Alternate inflation indexes-particularly the GDP price index, but also to some extent the PCE index - are not as attractive as they might appear. There might be a temptation 
at first to abandon the CPI in their favor because the basic design of these indexes is better than that of the CPI and they have been growing more slowly than the CPI in recent years. However, closer investigation reveals that these indexes have drawbacks of their own.

In sum, although the CPI does not measure true inflation, we currently have no thoroughly viable alternatives to it as an easy-to-use and fairly reliable guide to inflation movements. Although problems can arise when the CPI is used indiscriminately as a measure of the cost of living, the index does offer an appropriate starting point from which to make adjustments.

\section{Notes}

1. For example, see Lebow, Roberts, and Stockton (1992); Wynne and Sigalla (1994); and Shapiro and Wilcox (1996a).

2. An unrevised inflation measure like the CPI may be useful in determining annual cost-of-living adjustments in private contracts and government programs because revisions cannot be easily incorporated into indexing formulas. Nevertheless, if an inflation series is initially estimated incorrectly, it seems reasonable to revise it.

3. In April 1997, BLS released an experimental version of the CPI that addresses one technical problem contributing to the overstatement of price increases for individual items. Essentially, the new index makes an adjustment for the likelihood that consumers will shift their purchases to items on sale (Bureau of Labor Statistics 1997). BLS anticipates that this correction will cause the experimental index to grow perhaps $1 / 4$ of a percentage point more slowly than the standard CPI

Although the technical problem addressed is an important one, it has little bearing on our analysis of the relative strengths and weaknesses of the different price indexes. Because the GDP and PCE measures incorporate CPI data on individual prices, they share this problem with the CPI

The experimental BLS index will be issued on a monthly basis, one week after the regular report. BLS may eventually make it the official index.

4. A household is not as well off after this change is made as it was before the beef price increase. Nonetheless, the switch in buying patterns will leave the household better off than if it continued to buy the same amount of beef: the money saved by buying less beef and more chicken can be used for other purposes and will soften the blow of the beef price increase.

5. Quarterly readings of the chain-weighted series are not constructed using the Fisher Ideal method (Landefeld and Parker 1995).

6. Import prices will, of course, influence the price of domestically produced items through competitive pressure.

7. About three-fourths of the prices for individual items in the PCE, as gauged by expenditure share, are taken straight from prices of individual components of the CPI (Triplett 1996).

8. The difference in the importance of medical costs partly reflects a difference in the design of the two indexes. The CPI includes only out-of-pocket medical costs, while the PCE attempts to include all household medical expenses, no matter who pays for them. Both approaches can be justified. If the goal of an inflation measure is to capture the growth in the cost of all items consumed by households, it makes sense to include thirdparty payments to medical providers. In contrast, if one wishes to use changes in an overall price measure to index cash income, it may be better to include only out-of-pocket costs.

In addition, the medical price component of the PCE index has recently been growing more slowly than that of the CPI. This difference has also contributed a bit to the recent divergence between the two indexes. BLS is modifying its procedures for calculating the medical cost component of the CPI in the direction of those used in the PCE.

9. An additional concern in using the CPI or any other price measure to track inflation involves the filtering out of period-to-period noise in the data stemming from aberrant changes in a few individual prices (Bryan and Cecchetti 1993; Cecchetti 1996).

\section{References}

Boskin, Michael J., Ellen R. Dulberger, Robert J. Gordon, Zvi Griliches, and Dale Jorgensen. 1996. Toward a More Accurate Measure of the Cost of Living. Final Report to the Senate Finance Committee from the Advisory Commission to Study the Consumer Price Index. December 4.

Bryan, Michael F., and Stephen G. Cecchetti. 1993. "The Consumer Price Index as a Measure of Inflation." Federal Reserve Bank of Cleveland Economic Review 29, no. 3.

Cecchetti, Stephen G. 1996. "Measuring Short-Run Inflation for Central Bankers." Paper presented at the Conference on Measuring Inflation and Real Growth, Federal Reserve Bank of St. Louis, October.

Diewert, W. Erwin. 1976. "Exact and Superlative Index Numbers." Journal of Econometrics 4 (May).

1987. "Index Numbers." In John Eatwell, Murray Milgate, and Peter Newman, eds., The New Palgrave: A Dictionary of Economics. New York: Stockton Press.

Greenspan, Alan. 1997. Statement before the U.S. Senate Committee on Finance. Hearing on the U.S. economy and the budget. 105th Cong., 1st sess., January 30.

Landefeld, J. Steven, and Robert P. Parker. 1995. "Preview of the Comprehensive Revision of the National Income and Product Accounts: BEA's New Featured Measures of Output and Prices." Survey of Current Business 75 (July). 
Lebow, David E., John M. Roberts, and David J. Stockton. 1992. "Economic Performance under Price Stability." Federal Reserve Board Economic Activity Working Paper no. 125, April.

Shapiro, Matthew D., and David W. Wilcox. 1996a. "Alternative Strategies for Aggregating Prices in the CPI." Paper presented at the Conference on Measuring Inflation and Real Growth, Federal Reserve Bank of St. Louis, October.

1996b. "Mismeasurement in the Consumer Price Index: An Evaluation." National Bureau of Economic Research Macroeconomics Annual 12.
Triplett, Jack E. 1996. "Measuring Consumption: The Post-1973 Slowdown and the Research Issues." Paper presented at the Conference on Measuring Inflation and Real Growth, Federal Reserve Bank of St. Louis, October.

U.S. Department of Labor. Bureau of Labor Statistics. 1992. BLS Handbook of Methods.

1997. "The Experimental CPI Using Geometric Means." Research paper. April 10.

Wynne, Mark A., and Fiona D. Sigalla. 1994. "The Consumer Price Index." Federal Reserve Bank of Dallas Economic Review, second quarter.

\section{About the Author}

Charles Steindel is a vice president in the Business Conditions Function of the Research and Market Analysis Group.

The views expressed in this article are those of the author and do not necessarily reflect the position of the Federal Reserve Bank of New York or the Federal Reserve System.

\section{Recent Current Issues}

Date Vol./No. Title

1/97 3/1 1997 Job Outlook: The New York-New Jersey Region

1/97 3/2 The Effects of Price Limits on Trading Volume: A Study of the Cotton Futures Market

2/97 3/3 Debt, Delinquencies, and Consumer Spendin

3/97 3/4 Bad Debt Rising

4/97 Falling Reserve Balances and the Federal Funds Rate

\author{
$\operatorname{Author}(\mathbf{s})$ \\ Orr, Rosen \\ Evans, Mahoney \\ McCarthy \\ Morgan, Toll \\ Bennett, Hilton
}

Readers interested in obtaining copies of Current Issues in Economics and Finance through the Internet can visit our site on the World Wide Web (http://www.ny.frb.org). From the Bank's research publications page, you can view, download, and print any edition in the Current Issues series, articles from the Economic Policy Review, and certain issues of Staff Reports. You can also view abstracts for Staff Reports and Research Papers and order the full-length, hard-copy version of any paper in these series electronically.

Current Issues in Economics and Finance is published by the Research and Market Analysis Group of the Federal Reserve Bank of New York. Dorothy Meadow Sobol is the editor.

Editorial Staff: Valerie LaPorte, Mike De Mott, Elizabeth Miranda

Production: Graphics and Publications Staff

Subscriptions to Current Issues are free. Write to the Public Information Department, Federal Reserve Bank of New York, 33 Liberty Street, New York, N.Y. 10045-0001, or call 212-720-6134. Back issues are also available. 